\title{
Dynamics of community gardening: A catalyst for health
}

\author{
Donald N. Roberson, Jr. ${ }^{1, *}$ and Michal Kudlacek ${ }^{1}$
}

\author{
${ }^{1}$ Faculty of Physical Culture, Palacký University Olomouc, tr. Míru 117, 77111 Olomouc, Czech Republic; \\ dnrobersonjr@gmail.com (D.N.R.); michal.kudlacek@upol.cz (M.K.) \\ *Correspondance: dnrobersonjr@gmail.com.
}

\begin{abstract}
The purpose of this study is to investigate the perceived benefits of community gardening. A garden colony is a collection of adjacent plots of land primarily for the purpose of gardening. The methodology of this research consists of observations, interviews, questionnaires, and focus group. As a result of this research we found that gardening is a natural and safe way to meet the lifelong demands for a healthy life. We found specific mental and physical benefits as a result of this community gardening. We encourage communities to allow people to buy plots of land away from their homes to promote this healthy activity. The garden colony provides a place for individual renewal and restoration; this urban oasis offers a way to maintain and promote lifelong healthy living, and they are an important contribution to one's life by adding a sense of meaning and purpose.
\end{abstract}

Keywords: leisure; recreation; gardening; physical activity; natural landscapes

\section{Introduction}

Gardening is one of the common leisure activities throughout the world, gardening is more than spontaneous and random activity, and gardening can be a natural physical activity for promoting positive aging and health. This study is important because of its implications for older adults, but also for the ideas of free time. Not only did we find that there is an abundance of gardening taking place, we also found a natural fit for retirees within this outdoor activity. This being said, the purpose of this study is to understand more about the dynamics of gardening within a community gardening area. To this end we pursued two research questions what is the impact of gardening on the 1) mental as well as 2) physical aspect of the individual.

There are many places around the world where there are collections of gardeners. From small allotments to large pieces of land. These are usually outside of the urban area, and they are located within several kilometers of ones living area. If one is passing by quickly there is no notice, but a closer look reveals a very interesting scenario. One may see flowers growing, fruit trees, places for relaxation or playing, as well as a small cottage or shed for tools. Each one has its own unique story and character based on the gardeners. Also, in many situations they are surrounded by other gardeners which adds to the social dynamic.

This research focused on a garden area within central Europe. These garden areas or locally called 'colonies' are also a historical remnant of the Czechoslovak government. Moreover, the Communist regime that formerly controlled the government from 1948 until 1990, highly encouraged and even enhanced these garden plots. Because travel, especially travel in the west was restricted, in order to appease the population, small plots of land were made more accessible to citizens in order to encourage "local vacations" to spots the government trusted. The people built creative garden huts, weekend houses, places for barbeques, vineyards and surprised themselves by truly enjoying this experience and passing it on to the next generation. Interestingly, what the government intended as a way to appease the population has morphed into a classic expression of physical activity, leisure, nutrition, and community 
The other consideration is that these spots of nature, are small little parks, even miniature forests. Some gardeners may cultivate the land for vegetable and flowers, but most of the area is surrounded by forest, and has trees in abundance. Nature and forests dominate the area. People today proudly boast about their garden colony, spend weekends there with family and friends, and look forward to working in the soil for flowers and vegetables.

This activity which also is taking place in one's free time is similar to ideas from Park's [1] study indicating a positive and physical choice for retirees and older adults. It is accepted that older adults will have some chronic health problem that includes the typical changes due to biological aging. This implies a general lessening in functional ability in all areas of the body, including psychological and emotional issues. Maas, Verheij, Spreeuwenberg, Schellevis, and Groenewegern [2] show that because of the expanse of urban areas, because of the increasing amount of people living in cities, people in general are living in less green spaces. From their research we know the positive impact of being in a green environment. Further, they showed there are less older adults who have morbidity if they are around a green environment as well as less depression or stress. Continuing these ideas, the research of Vuillemin, Boini, Bertrais, Tessier, Oppert, Hercberg, Guillemin, Brianc [3] investigated health, quality of life, and leisure activity. Not surprising, this large project showed that those with physical active behavior had overall higher quality of life than those who were more sedentary. The significance of being around natural green areas was also shown by Stigsdotter and Grahm [4] how gardening can be a type of therapy with patients who have various mental needs. The programs the therapists design for the participants are focused on the garden.

Kaplan [5] follows the ideas of Stigsdotter and Grahm [4] by discussing the overall positive and restorative influence of nature. Physical and mental dimensions are more restored while being in a natural environment. This takes place by being away from normal situations and spending time in some natural environment. This place should also include something that fascinates us, something that engrosses us. This pre-occupation with the natural environmental actually allows the individual to also think about other important topics. There should also be an aspect of extent, something that shows that we are connected to a larger world.

Heintzman's [6,7] research helps to show how being outdoors in natural settings influences the person. He describes how specific activities such as gardening, or time away in the nature, helps to elicit some special feelings of well-being even with spiritual overtones. Adding to this is Park's [1] conclusions outlining the positive aspect of natural work in the outdoors and how it strengthens the physical structure of the body. Further, because of its slower pace and natural setting, its almost idea for older adults. Similarly, Patrick, Bassey, Irving, Blecher, and Fentem [8] discuss physical activity of retired adults. They mention how walking and gardening are popular among this age group. However, they point out that measuring physical activity is difficult among those who need it the most - the retired, aged, overweight, and sedentary. Even among those who are the least active, walking and then gardening are among the most popular physical activities.

More people today are living in urban areas or cities with crowded and noisy situations. Rural life has declined steadily since the start of the Industrial Revolution when businesses offered financial reward to those who were willing to work in factories. These agrarian workers left behind farms, ponds, animals, quiet, and a more leisurely way of life [9]. Since this era, free time within today's modern society has become even more congested. Citizens seem to be frustrated at the lack of meaningful free time in their lives. Also, work and family demands continue to add pressure on an already harried population.

Adding to this, there is a need to provide places for safe and effective physical activity throughout one's lifetime. Physical activity can waiver between sporadic mundane workouts to trendy facilities with the latest fads in health and fitness. The increase in medical expenses, as well as the rise in preventable diseases such as Type 2 Diabetes, and the lack of physical education in our schools [10,11], call for a revision of our concept of 
physical activity, recreation, and free time. Therefore, we can state that gardening may be the new way for each person around the world to fill their free time, continue to provide for themselves, offer social visits, and take care of the physical dimensions. Therefore, it is important to understand more details about this leisure activity. With this in mind we endeavored to investigate the gardening activity in our area.

The purpose of this study is to understand more about gardening in a natural area. To this end we are focused on two research questions - What is the physical impact on the gardener? And, what is the mental impact on the gardener? Even though previous research highlights potential benefits of gardening for physical health, there is a lack of detailed knowledge [12] about the nature and perceived health benefits of these gardening activities, particularly within the garden colony context.

\section{Materials and Methods}

This subjective experience can best be understood using qualitative methods [13]. This study utilized a combination of mixed methods including interviews [14], questionnaires [15], a focus group [16], observation [17 ] and case study [18]. Before beginning this research we were careful to gain the necessary approval, and we asked each person for written permission if they wanted to be a part of this project. Because we were outsiders to this garden colony, we sought to listen, and to attend to the gardeners with empathy [19]. This research had the ethical approval required by this university. The summary of research activity is depicted in Figure 1. 


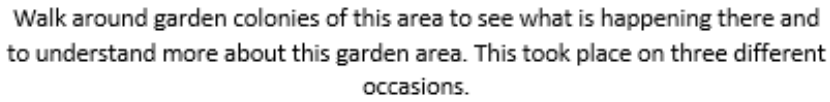

Walk around garden colonies of this area to see what is happening there and to understand more about this garden area. This took place on three different occasions.

During the 'walk about,' we asked several people of one garden colony if they would be interested in this research. We found two people that were willing to participate in this research. The initial survey with a pedometer with two participants in garden colony. June 2009.

We met with these two people; this helped us to gain insights into the life of the garden colony of Olomouc. They showed us their garden area and explained what they were doing there.

From this information as well as research we had read, we created a Garden survey given to U3A class. This gave us a general idea of gardening among the population of this area, this was in December 2009.

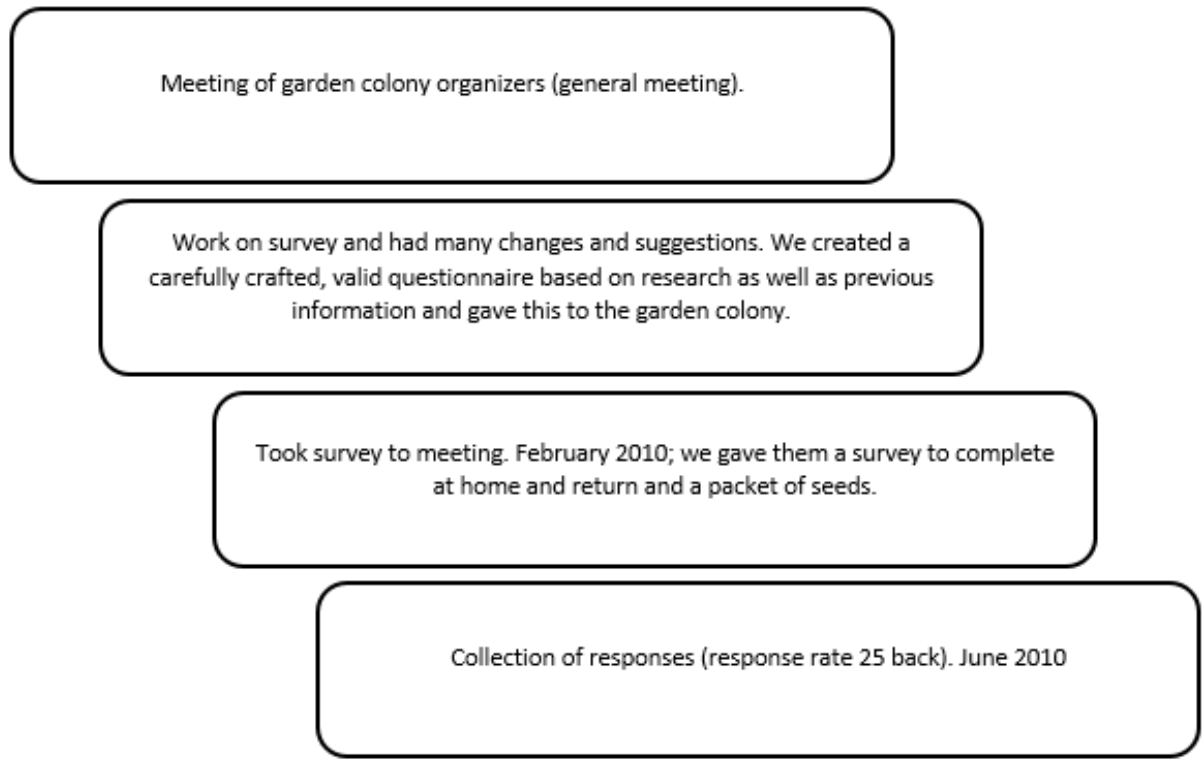

Figure 1. Summary of research activity.

\subsection{Stage One: Observation and Pilot Study}

First, we walked around various gardens and observed what we saw taking place. We created a questionnaire in combination with a pedometer and a journal, and we asked for volunteers to fill out the survey. Eventually, after four months, two participants completed a journal, showed us their garden area, wore a pedometer, and explained the details of gardening.

\subsection{Stage Two: Questionnaires}

In order to learn more about gardening in this area we created a questionnaire based on previous research. We asked an adult education class at the university for their opinion (University of the Third Age.) Out of 50 participants we received 21 responses. After reviewing the results of this, we revised the questionnaire to create a more valid questionnaire. This questionnaire was given to the participants of the garden colony; this took place at their annual meeting (see Appendix 1). Eventually, the person in charge returned 24 questionnaires out of 81 attending the meeting. After analyzing this data, we invited those interested to join a focus group of gardeners. 


\subsection{Stage Three: Focus Group}

Now there are several sources of data - questionnaire one, questionnaire two, interview and information from two participants, and field notes. During the focus group we asked the participants to describe more about their gardening. They also elaborated on some of the findings so far. We analyzed the data using constant comparative method $[18,20]$. We separately evaluated and read the survey and combined our ideas and thoughts. In this method of analysis we compared the main parts of the data obtained within this research, and we were looking for differences and similarities. We wrote down notes and different ideas that reflected a continuous comparison of the data. We asked the focus group to confirm or validate our findings. As a result of this work, we eventually arrived at the findings of this study. All conversations during the focus group were translated and transcribed by reliable sources.

\subsection{Stage Four: Continued Observation}

Lastly, we continued to go to the garden colony and to observe the gardening activity in order to verify our findings. On June 5 (Saturday) and June 6 (Sunday) 2010 we visited the garden colony to observe and record the activities in the summer. On Saturday we saw many gardeners, some with entire families, inside their private garden area. The small road surrounding the colony was lined with cars. We saw many people in those unique and interesting situations of active gardening. These gardeners were on their knees pulling things, bending over reaching for something, working in the dirt, cutting, seeding, and watering. Many of them were working in bathing suits. Their attention was on their garden, and they were walking around talking with their partner or families, going from task to task. We also observed other activities in the garden such as reading, sitting, eating, cooking (outdoors), and children playing. This combination of information from observations, documents, interviews, questionnaires, and focus group has provided us with a triangulated analysis on gardening (Patton, 1990). This research took approximately two years to complete from beginning to end. During this period there was ample time for reflection concerning these ideas and thoughts about gardening. There was a peer review as well as a member check [18] in order to verify these findings. The focus group and the first two individuals we interviewed confirmed our findings as well.

The findings of this research were the result of the combination of these various sources of data. Personal observation, studying previous research, survey on gardening, interaction with two participants, validated questionnaire, and a focus group. The information was coded according to how it answered the purpose of the student and the research questions. All of the necessary requirements for research with the university were met.

\section{Results}

In order to understand the role of gardening in this area we asked a class from an adult education program in this area (University of the Third Age) to fill out an investigative questionnaire on gardening. The average age was 63.6. The mean 63.6, median 63 and age range was $54-72$ years of age. Out of 50 attending the class, 21 participants completed the survey - all 21 had a garden nine of these gardens were located in a colony, and twelve had gardens at their home. We began to understand the pervasive character of gardening in this area. Those with a garden in the colony spent a considerable more time there. Whereas the garden at home was utilized for growing vegetables for use in cooking and eating with one's family and friends. The garden at home was seen more as a chore in comparison with those who had a garden at the colony.

From other parts of this research, we found that the summer or warm months are a very active time for the participants of the garden colony, whereas during the winter it is rare. Concerning transportation, we found 13 people have gardens one to three kilometers from their residence, ten gardeners are three to five kilometers, and one is five to ten kilometers away from the garden. It took 15 minutes for 15 people to get to their garden. 
Another eight gardeners needed 30 minutes and one person needed one hour. The most common way of transportation was bicycle $(\mathrm{n}=14)$, followed by car $(\mathrm{n}=8)$, then walking $(n=5)$ and bus $(n=4)$. Nineteen out of 24 participants were biking or walking to their garden colony, thus adding an additional amount of physical activity to their day. The frequency of working in the garden colony can be seen in Figure 2.

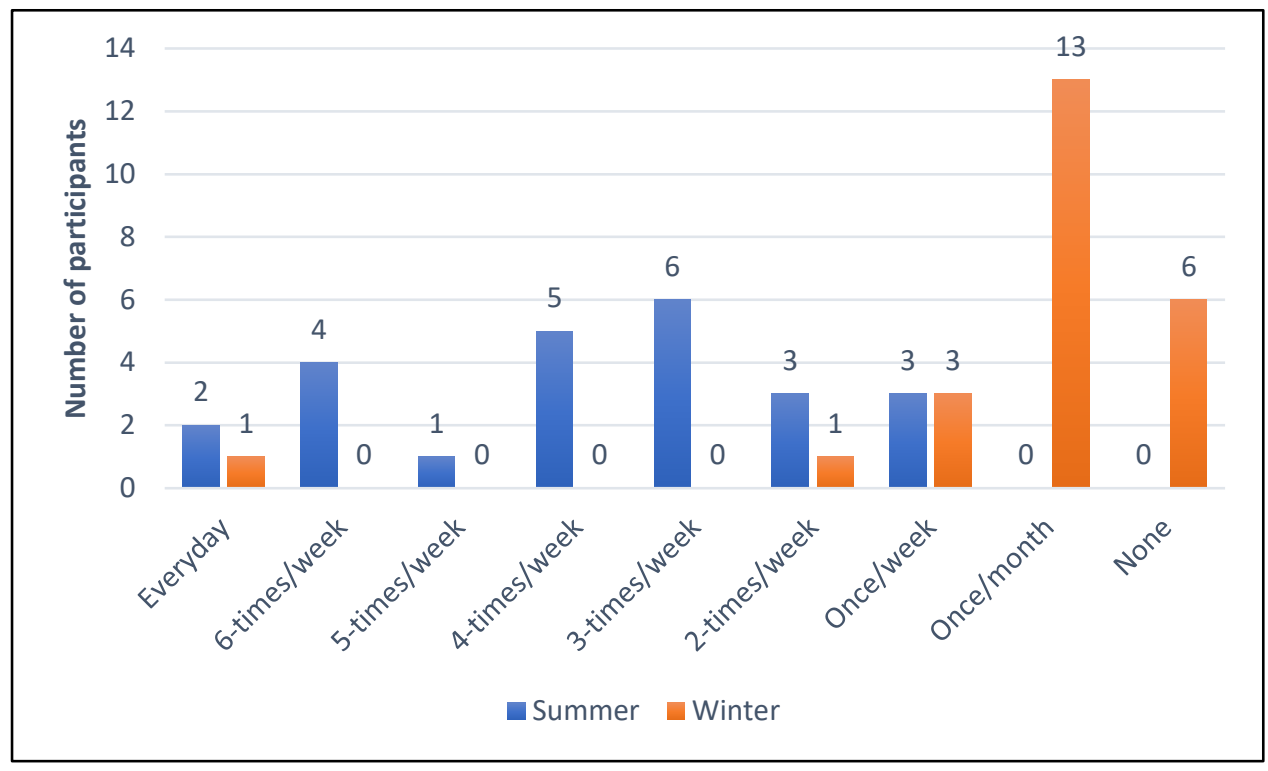

Figure 2. Frequency of going to garden.

All of the gardens within the colony are basically the same size $\left(400 \mathrm{~m}^{2}\right)$. We also found that a large proportion - almost one fourth - of the garden area $\left(117 \mathrm{~m}^{2}\right)$ is covered with a natural grass area. We discovered that the garden activity is focused on trees, vegetables, and flowers. Each garden has a small sitting area and often a small one room crafted cottage. The gardeners discussed how garden colonies are a part of life across central Europe, not just in the Czech Republic. They said that within the garden colony the gardeners know those who are next to them; yet, they recognize by sight some of the other gardeners. One said, "It is a big colony, but we only know our neighbors." However, the garden is not without its own set of problems. They discussed that there are some frustrations with gardening in the colony such as problems with insects and slugs. One person said:

In the colony are lots of pests...so we focused on the fruit trees...and we gradually liquidated them....and now we are focusing on the decorative part, the relax part, and from the vegetable I grow only tomatoes, cucumbers, some salad in the spring, and I mainly take a pleasure from the flower part.

As a result of this research we found from our participants two main results. First, having a space within this natural area becomes a source of restoration, rest and quiet. Second, the gardeners are meeting the requirements for physical activity as a result of the work within this natural area.

One - Mental - Restoration and Quiet.

One participant explained that working in the garden colony was more than rest or relaxation. It felt like recreation with a purpose. Rather than wandering in some forest trail for activity, this activity inside the garden creates specific results which they can see and taste. They also emphasized there is an emotional reward for being a part of this activity. There is excitement about the changes that one can see from the plants. Another stated that when she wants she will "go to have a nice chat with my neighbor." Another gardener emphasized the complexity of the experience. "You just don't know what will take place, weather, your neighbor, or the soil, how the plant will turn out, it all adds to the fun and challenge. "The growing of vegetables, and eating or sharing them is an important part of this work. Also, having neighbors that surround you is an overall pos- 
itive part of this garden colony. One gardener said that even in the winter he was compelled to return to the garden, at least once a week, just to feed the wildlife.

The enjoyment of going to the garden in the colony is indicated by the Figure 1 which indicates the frequency of attending to one's garden. One gardener explained how her family used the garden area for a place for children to play and a place to grow organic vegetables. She further explained that the garden area away from the town provides its own quiet escape away from the noise of the urban area. And how her chidren can safely run and play. Plus they are enjoying the organic vegetables. Another gardener emphasized how having this garden area with others provides its own sense of happiness and personal peace of mind. He discussed how in each season his family will enjoy attending to the needs of the garden.

All of the participants in the focus group stress how it adds to their situation by having neighbors around them. Some you become lifelong friends, others you may leave alone. "You begin to know who you can count on, and who you want to invite for a campfire, and who you need to leave alone." The other activities that take place in the garden are seen in Figure 3.

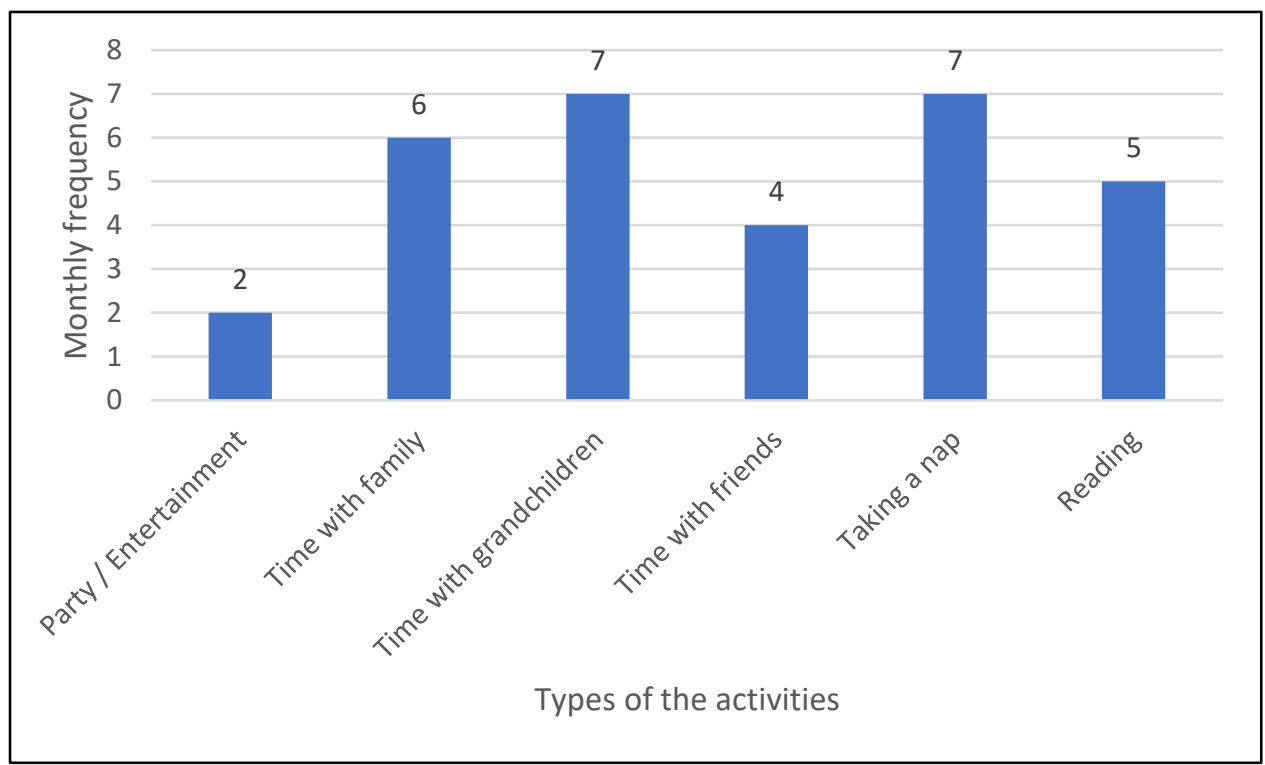

Figure 3. Other activities in the garden.

All of the participants are in agreement that this collective gardening is a place for relaxing, enjoying, and promoting a peace of mind.

Two - Physical - The second finding focused on the physical aspect of gardening. The gardeners discussed how maintaining this plot of land there is adequate physical activity to provide for a healthy lifestyle. Figure 2 indicates the overall pervasive physical dynamic of working in the garden.

Participant One, age 73, spent a total of 22 hours in gardening activity during her week of gardening. Participant Two, age 68, spent a total of 12 hours in gardening activity. They used various statements to explain what gardening meant to them: "active movement," "stay on the fresh air," "replacement of former activity in their flats and in the town," and "communication with neighbors." Adding to this from the first questionnaire we found there are those who have a garden at home, and those who have a garden in a collective garden area. As a result of information from the two participants in the beginning of this study, we found they both spent a considerable amount of time working in their garden. One, 22 hours per week, and another 12 hours per week. They also emphasize being active in the fresh air is what they are looking forward to. Surprisingly, those who had a garden at their home spent 21 hours per year in their garden, in contrast, those who had a garden in a colony spent approximately 200 hours per year. The Garden colony activity can be seen in Figure 4. 


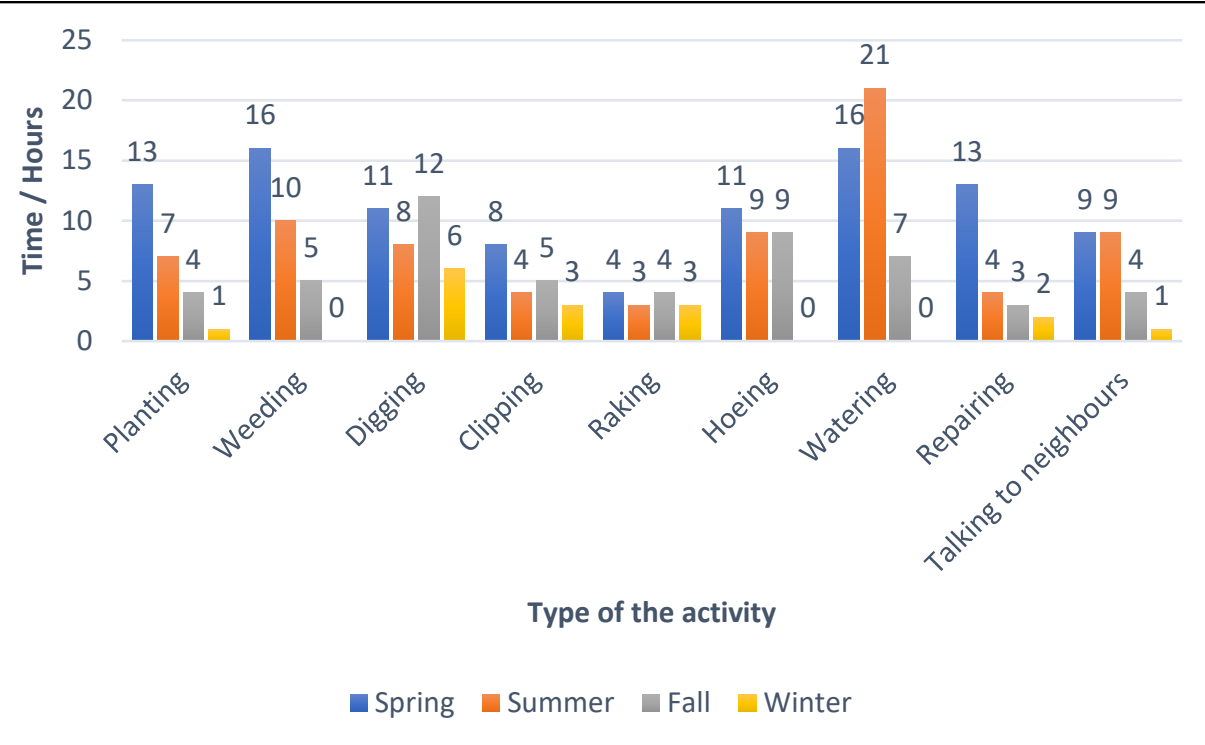

Figure 4. Garden activities in four seasons.

As a result of this questionnaire we know that the gardener is having an all-around physical workout during three seasons, especially in summer and spring. During the spring there is an average of 6.7 hours of physical activity each week, in the summer 5.2 hours weekly, in the fall 3.5, and in the winter 1.1. This indicates these gardeners are meeting the daily requirement of physical activity during spring, summer, and fall. In addition they are utilizing all muscle groups in a natural environment. Another gardener stated: "We take it like a sport. We will walk there, or ride bike, and then garden, work in the garden, even in the winter, we will go there and feed the cats."

We also asked their opinion of the influence of gardening on their health. How (in your opinion) does having this garden influence your health? Nine participants stated they knew that gardening was overall positive for them. Six also stated how it relaxes them, especially by "cleaning my thoughts" or "taking care of stress." Six of the gardeners emphasize how they know the garden is adding to their physical fitness, and three mentioned mental fitness. Five participants said the value of being around nature was positively influencing their health. Interestingly, only three gardeners discussed the actual gardening or growing of fruits and vegetables. And two added that gardening may cause low back pain. A summary of these answers can be found in the response of one gardener, who said the following. "It (gardening) keeps me in good shape both - physically and mentally. The nature is giving us not only joy of the colors of the blooms, their smells, work of the bees and bumblebees, but also the food." Having a "good feeling about the results of our work" was mentioned by five. "Common work or physical movement" was mentioned by three. 


\section{Discussion}

This garden colony presents an interactive community within a natural built environment. This research resonates with Hawkins et al. [12] who included 25 allotment gardeners. Although our research focused on gardens within a common area and each one is almost 200 meters square. They saw similar benefits such as personal enjoyment, physical strength, fun time with friends and family. Even though community gardens in the west are rare, some American cities, are sharing small areas for gardening. The gardening represented in this study is a unique phenomena and perhaps something influence by the previous regimes in central Europe. Others have noticed these areas of gardening are changing and even closing, perhaps due to a busier perspective as well as the use of land [21]. Perhaps areas for gardening could add to the urban built environments incorporating urban planning and result in more 'walkability' [22].

The participants in our study made it clear how much they enjoyed and looked forward to being in this natural area. Heintzman [6,7], Kaplan \& Kaplan [23], Schroeder [24], and Ulrich \& Parsons [25] similarly focused on the peace and quiet and its benefits that is found in such natural places. All of these reports concur that the outdoor place in its natural settting along with this gardening lessens stress, increases spirituality, and well being. This gardening even becomes its own therapy reflecting ideas of Hawkins et al. [12] and Nordh et al. [26].

One participant explained how they chose to get a garden in a colony because they needed to start moving and becoming more active. And, interestingly you are also surrounded with others and their gardens. With our participants, almost half of them were involved and close with their neighbors, the others not.

Attention Restoration Theory [5] and its concepts were expressed by several gardeners. Similar to 'a place of escape' as well as [27] fascination, these participant felt renewed and restored each time they return to the garden area. One participant says he is looking forward to something every season. And how the garden is a way to get away from the crowded block of flats where he lives.as a result of getting away from their flat in the city. Also Herzog et al.'s [27] ideas are seen in the participant's complex leisure activities - time with others, relaxing, working on flowers or fruit. Kaplan [5] states the area of interest should be very appealing for all the senses. The participants discussed the variety of trees, flowers, vegetables, grass, a cottage, and sheds. Another participant discusses how going to the garden area produced pure joy.

The garden is a place that can promote purpose such as growing fruits and vegetables, caring for trees, raising chickens, or providing a fun space for the family. The participants in our study described the restorative qualities as discussed by Herzog et al. [27]. Their narrative echoed the soft fascination linked to growing vegetables and flowers, seeing the results and enjoying the simple beauty and quiet of the natural surroundings. They also described the sense of being away, leaving one's flat, and going to the garden. They mentioned how the variety of activities in the garden plot are compatible with their individual interests and sense of purpose, especially taking care of trees and vegetables, and the enjoyment of spending time with family and neighboring gardeners. Further, adding to the dynamic of the garden plot, often the small cottage was a creative handiwork of its owners. All shapes, sizes, unique forms of wood helped to lend to the magic of the area.

This paper highlights garden colonies as a historical and ecological feature within the Czech Republic. Reflecting ideas of place and identity [28,29], we also saw how the gardeners in our study were personally attached to these green urban places and looked forward to spending leisure time at the garden. One member of the garden colony reflected the ideas of most when she said, "I look forward to getting out of my flat and getting to the garden." This family ritual was part of their identity, and the various activities of gardening became a priority. As their world adapted from Czechoslovakia to a Nazi occupation, the Second World War, the changes due to forty years of communism, and to a new democracy - the space of the garden provided a safe and personal sense of continuity and stability. One person described their garden: "We made a cottage there 
and at the beginning we grew a lot of everything...all kinds of fruits and vegetables...but it became difficult...and now we focus on the flowers and the relaxation." Today the garden colony is no longer needed to grow supplements for one's diet, there are vast grocery stores within the reach of every hamlet and village. Instead, the garden colony has become a place for exercise, leisure, and social interaction. Another change since the fall of communism, there has been a relaxation of some of the rules for the colony, for example they can build larger cottages. The social connection around these gardeners reflects a wide range of interest from close frineds, to asking an expert, to someone to avoid [30] [31].

From the sample in our study, gardening is an enriching experience especially for seniors and those who are retired, especially those who are living in crowded cities or city blocks. Similarly, Patrick, Bassey, Irving, Blecher, and Fentem [8] discussed the more popular physical activities of retired adults which included walking and gardening. We were surprised to find from our questionnaire with a class of older adults (U3A), that all 21 participants stated they had a garden. Furthermore, Mein, Shipley, Hillsdon, Ellison, and Marmot [32] found that those who are retired are actually more involved in physical activities, and that gardening, similar to ideas of Park [1], Park et al. [33,34] as well later studies of Park, Lee, \& Son [35] and Park, Lee, Son, \& Shoemaker [36] can supply the necessary physical activity for a healthy life. Similar to Park's work we also found that most of the gardeners are involved in this dynamic activity of weeding, hoeing, watering, and walking. Plus, the moderate activity of gardening is a natural way to exercise the body in an enjoyable manner. Adding to this line of thought, Podewils et al. [37] discussed how engaging in a number of different physical activities, including gardening, can protect the senior against various problems of aging especially that of dementia and Alzheimer's disease.

\section{Conclusions}

As a result of this research we found that gardening is a natural and safe way to meet the lifelong demands for a healthy life. Having a space within the garden colony adds a sense of purpose, identity, and meaning to one's life. This area of nature is a source of restoration as a result of rest, escape, and quiet. Further, gardening allows for all the muscles within the body to work in a natural setting promoting personal health. In conclusion, we recommend gardening as a natural physical activity. This is a great example and beacon of light for the future, to rekindle an old idea, something that has lasted over the years and can create a safe and quiet place for a renewal of the social, physical, mental, and spiritual part of one's life.

Author Contributions: D.N.R. conceptualized the study design, contributed to the data collection, analyses, data interpretation and writing of the manuscript. M.K. contributed to the data collection, data analysis, project administration writing - revision and editing. Both authors have read and agreed to the published version of the manuscript.

Funding: This research received no external funding.

Institutional Review Board Statement: The study was conducted according to the guidelines of the Declaration of Helsinki and approved by the Ethics Committee of the Faculty of Physical Culture, Palacký University Olomouc.

Informed Consent Statement: Informed consent was obtained from all subjects involved in the study.

Data Availability Statement: The data presented in this study are available upon request from the corresponding author.

Conflicts of Interest: The authors declare no conflict of interest. 


\section{References}

1. Park, S. Gardening as a physical activity for health in older adults. Doctoral dissertation, Doctor of Philosophy, Kansas State University, 2007.

2. Maas, J.; Verheij, R.A.; Spreeuwenberg, P.; Schellevis, F.G.; Groenewegen, P.P. Morbidity is related to a green living environment. J. Epidemiol. Community Health 2009, 63, 967-973.

3. Vuillemin, A.; Boini, S.; Bertrais, S.; Tessier, S.; Oppert, J-M.; Hercberg, S.; Guillemin, F.; Brianc, S. Leisure time physical activity and health-related quality of life. Prev. Med. 2005, 41, 562- 569

4. Stigsdotter, U.A.; Grahn, P. Experiencing a garden: A healing garden for people suffering from burnout diseases. J. Ther. Hortic. 2003, 14, 38-49.

5. Kaplan, S. The restorative benefits of nature: Toward an integrative framework. J. Environ. Psychol. 1995, 16, 169-182.

6. Heintzman, P. A conceptual model of leisure and spiritual well-being. J. Park. Recreat. Admin. 2002, 20(4), 147-169.

7. Heintzman, P. Leisure and spiritual well-being relationships: A qualitative study. Soc. Leis. 2000, 23(1), 41-69.

8. Patrick, J.M.; Bassey, E.J.; Irving, J.M.; Blecher, A.; Fentem. P.H. Objective measurements of customary physical activity in elderly men and women before and after retirement. Q. J. Exp. Physiol. 1986, 71, 47-58.

9. De Grazia, S. Of Time, Work, and Leisure. The Twentieth Century Fund, New York, NY, 1961.

10. Kudlacek, M.; Fromel,; Kren, F.; Bebcakova, V. Struktura sportovních preferencí studentů středních škol. Tel. Vých. Šport. 2007, 17(3-4), 10-13.

11. Wallhead, T.L.; Buckworth, J. The role of physical education in the promotion of youth physical activity. Quest, 2004, 56(3), 285-301.

12. Hawkins, J.L.; Thirlaway, K.J.; Backx, K.; Clayton, D.A. Allotment gardening and other leisure activities for stress reduction and healthy aging. HortTechnology. 2011, 21, 577-585.

13. Peshkin, A. The goodness of qualitative research. Educ. Res. 1993, 22(2), 24-30.

14. Seidman, I. Interviewing as Qualitative Research: A Guide for Researchers in Education and the Social Sciences. Teachers College Press: New York, NY, 1998.

15. Mason, J. Qualitative researching. Sage: San Francisco, CA, 1996.

16. Patton, M.Q. Qualitative Evaluation and Research Methods, 2rd ed.; Sage: Newbury Park, CA, 1990.

17. Bogdan, R.C.; Biklen, S.K. Qualitative Research for Education: An Introduction to Theory and Methods, $2^{\text {nd }}$ ed. Allyn and Bacon: Boston, MA, 1992.

18. Merriam, S. B. Qualitative Research and Case Study Applications in Education. Jossey-Bass: San Francisco, CA, 1998.

19. Gair, S. Feeling their stories: Contemplating empathy, insider/outsider positionings, and enriching qualitative research. Qual. Health. Res. 2011, 21(1), 134-143.

20. Dey, I. Qualitative Data Analysis: A User-Friendly Guide for Social Scientists. Routledge: New York, NY, 1993.

21. Paukerova, K.; Gabas, P. The struggle over nature and relaxation in suburban space: The case of garden colonies in Kbely, Prague $19 . \quad$ Available online: https://www.academia.edu/1109758/The_struggle_over_nature_and_relaxation_in_sub_urban_space_the_case_of_garden_col onies_in_Kbely_Prague_19 (accessed on October 19, 2011).

22. Dygryn, J.; Mitas, J.; Stelzer, J. The influence of built environment on walkability using geographic information system. J. Hum. Kinet. 2010, 24, 93-99.

23. Kaplan, R.; Kaplan, S. The Experience of Nature: A Psychological Perspective. Cambridge University Press: Cambridge, UK, 1989.

24. Schroeder, H.W. Preference and meaning of arboretum landscapes: Combining quantitative and qualitative data. J. Environ. Psychol. 1991, 11, 231-248.

25. Ulrich, R.S.; Parsons, R. (1992). Influences of passive experiences with plants on individual well-being and health. In The Role of Horticulture in Human Well-being and Social Development: A National Symposium, Relf, D. Ed.; Timber Press: Portland, OR, 1992, pp. 93-105.

26. Nordh, H.; Grahn, P.; Wahrborg, P. Meaningful activities in the forest, a way back from exhaustion and long-term sick leave. Urban. For. Urban. Green. 2009, 8, 207-219.

27. Herzog, T.R.; Black, A.M.; Fountaine, K.A.; Knotts, D.J. Reflection and attentional recovery as distinctive benefits of restorative environments. J. Environ. Psychol. 1997, 17, 165-170.

28. Twigger-Ross, C.L.; Uzzell, D.L. Place and identity processes. J. Environ. Psychol. 1996, 16, 205-220.

29. Williams, D.R.; Patterson, M.E. Place, leisure and wellbeing. In Sense of Place, Health and Quality of Life, Eyles, J., Williams, A., Eds.; Ashgate Publishing Ltd.: Hampshire, NE, 2008, pp. 105-120.

30. Wang, H-X.; Karp, A.; Winblad, B.; Fratiglioni, L. Late-life engagement in social and leisure activities is associated with a decreased risk of dementia: A longitudinal study from the Kungsholmen Project. Am. J. Epidemiol. 2002, 155(12), $1081-1087$.

31. Kingsley, J.Y.; Townsend, M.; Henderson-Wilson, C. Cultivating health and wellbeing: members' perceptions of the health benefits of a Port Melbourne community garden. Leis. Stud. 2009, 28(2), 207-219.

32. Mein, G.K.; Shipley, M.J.; Hillsdon, M.; Ellison, G.T.H.; Marmot, M.G. Work, retirement and physical activity: Cross sectional analyses from the Whitehall II study. Eur. J. Phys. Health. 2005, 15(3), 317-322.

33. Park, S.; Shoemaker, C.A.; Haub, M.D. A preliminary investigation on exercise intensities of gardening tasks in older adults. Percept. Mot. Skills 2008, 107, 974-980.

34. Park, S.; Shoemaker, C.A.; Haub, M.D. Physical and psychological health conditions of older adults classified as gardeners and non gardeners. HortScience. 2009, 44(1), 206-210. 
35. Park, S.; Lee, K.; Son, K. Determining exercise intensity of gardening tasks as a physical activity using metabolic equivalents in older adults. HortScience. 2011, 46(12). 1706-1710.

36. Park, S.; Lee, K.; Son, K.; Shoemaker, C. Metabolic cost of horticultural activity in older adults. J. Jpn. Hortic. Sci. 2012, 81(3), 295-299.

37. Podewils, L.J.; Guallar, E.; Kuller, L.H.; Fried, L.P.; Lopez, O.L.; Carlson, M.; Lyketsos, C.G. Physical Activity, APOE Genotype, and Dementia Risk: Findings from the Cardiovascular Health Cognition Study. Am. J. Epidemiol. 2005, $161(7), 639-651$. 